\title{
A new glimpse on trophic interactions of 100-million-year old lacewing larvae
}

Marie K. Hörnig, Christine Kiesmüller, Patrick Müller, Carolin Haug, and Joachim T. Haug

Acta Palaeontologica Polonica 65 (4), 2020: 777-786 doi:https://doi.org/10.4202/app.00677.2019

Larvae of lacewings (Neuroptera) are known to be fierce predators. According to the morphology of fossil forms thisseems to have been the case already in the Early Cretaceous. While being predators, lacewing larvae are also food itemsfor other organisms. Here we report two pieces of amber from Myanmar providing instances of such cases. In one amberpiece several isolated stylets of lacewing larvae are preserved closely associated together. The most likely interpretationis that a predator preying on lacewing larvae has regurgitated or defecated these non-digestible pieces, yet the identityof the predator remains unclear. The other amber piece preserves a larva resembling modern day larvae of split-footedlacewings (Nymphidae). The larva has projections on its trunk, allowing it to wear a camouflaging cloak. In the headregion, a mite (Acari) is attached to the larva; more precisely, the entire anterior body region of the mite is apparentlyinserted into the lacewing larva. The mite is smaller than the larva. It is known from the modern fauna that stage 1 larvaeof Ascalaphidae can be attacked also by rather small predators, such as ants. The mite can therefore well be interpretedas a true predator instead of a parasite, especially considering the unusual mode of attachment. We briefly review interactionsof lacewing larvae with other organisms represented in amber from Myanmar and add two new pieces to thepuzzle of reconstructing the trophic interactions in the 100-million-year old amber forest.

Key words: Neuroptera, Nymphidae, food-web reconstruction, Burmese amber, larvae, syninclusions, Cretaceous, Myanmar.

Marie K. Hörnig [marie.hoernig@palaeo-evo-devo.info] and Christine

Kiesmüller [c.kiesmueller@gmx.de], University of Greifswald, Zoological Institute and Museum, Cytology and Evolutionary Biology, Soldmannstr. 23, D-17489

Greifswald, Germany. Patrick Müller [pat14789@web.de],

Friedhofstr. 9, 66894 Käshofen, Germany. Carolin Haug [carolin.haug@ palaeo-evo-devo.info ] and Joachim T. Haug [joachim.haug@ palaeo-evo-devo.info], Ludwig-Maximilians-Universität München (LMU), Biocenter, Großhaderner Str. 2, 82152 Planegg-Martinsried, Germany and GeoBio-Center, Ludwig-Maximilians-Universität München, Richard-Wagner-Straße 10, 80333 München, Germany. 
This is an open-access article distributed under the terms of the Creative Commons Attribution License (for details please see creativecommons.org), which permits unrestricted use, distribution, and reproduction in any medium, provided the original author and source are credited.

For Full text $(1,405.2 \mathrm{kB})$ 